\title{
Graduates Higher Education and Career Interlink of the College of Arts and Sciences of Central Bicol State University of Agriculture-Calabanga Campus
}

\author{
DARIEL A. PALMIANO \\ Central Bicol State University of Agriculture-Calabanga Campus
}

\begin{abstract}
A purpose-driven and effective tertiary education and training system is basic to generating competent and essential high-level skills, values, and knowledge vital for the socio-economic development of a country. The study traced the Bachelor of Arts in English Language (ABEL) and Bachelor of Science in Mathematics (BSM) of the College of Arts and Sciences (CAS), Central Bicol State University of Agriculture (CBSUA)- Calabanga Campus who graduated between 2011 to 2015 in terms of their job placement profile and the usefulness, relevance, effectiveness and adequacy of the skills and competencies as well as work-related values to their job placement. A survey method using questionnaire was utilized to 188 respondents. Results revealed that most of the respondents landed on jobs which were related to their course, were employed in less than a month, but stayed on their job only for about 1-6 months. A large percentage were gainfully employed as office employees. The primary reason for some of their unemployment was that they did not actively seek work. Many were employed because of their area of specialization and acquired their employment thru the personnel office of hiring companies. Communication skills and love of God were the most useful and relevant and critical thinking skills was the most effective in finding their job. As to work-related values, there were adequate trainings on self-discipline and self-reliance; whereas, honesty and love for truth as well as the love of God had become the most effective to their current employment.
\end{abstract}

Keywords. Tracer study, ABEL \& BSM graduates, job placement, skills and competencies, work related values DOI: $10.7176 / \mathrm{IKM} / 9-4-02$

Publication date: April $30^{\text {th }} 2019$

\section{Introduction}

1.1. Background

Higher Education Institutions are fundamental building blocks for human development, a powerful driver for individuals and society. Tertiary education systems are generally too small to meet the demands of their growing economies particularly along improving health, gender equality, peace, and stability. HEIs respond to three distinct national goals: The education of the youth to become active and productive members of society; The seeks to meet and match industry demand with a competent and globally competitive workforce; and, finally, through a continuing effort to reach global education standards, through increasing the quality of human capital and productivity vis-à-vis national and economic progress (Buama, 2018).

There are many reasons for going to university, including - naturally - a love of the subject to be studied, and the opportunity to experience a different way of life. Higher education is much more than a production line for work-ready graduates. There is no denying that people see higher education as a stepping stone to a good job. In $2010,73 \%$ of the students who took part in the Sodexo University Lifestyle Survey1 said they went to university to improve their job opportunities (Kevin Lowden, Stuart Hall, 2011).

The literature on graduate employability shows that there has been a range of attempts by HEIs to address graduate employability. However, the extent to which such developments are happening and the level to which they are embedded across the Higher Education sector is unknown but seems highly variable. This is despite key developments in government policy to encourage HEIs and employers to work together to develop approaches that contribute to graduate employability (Allison et al 2002).

In his speech in the Seminar entitled "Enhancing Graduate Employability: Issues, Concerns and the Way Forward (as cited by Ramirez and Cruz, 2014), Nordin (2009) stated that: "Today's challenging economic situation is no longer sufficient for a new graduate to have knowledge of an academic subject; increasingly students have to gain skills to enhance their employability. Hence, Higher Education Institutions must be responsive to these changes. Historically, academic institutions serve as institutions for the development of moral and intellectual aspects of every student and centers of civilization. However, with rapid economic development, they become more utilitarian putting much more value on professional training over all others. Their prime task now focuses on education and training that are market-driven and responsive to the changing needs of the various sectors of an economy."

Education has become an essential part of everyone's life in which it gives added values to each, in particular, those who excel in their studies. Regardless of whether the institution is a public or a private 
institution, students' performance always is a major concern. According to Emmanuel (2007), students' performance can be influenced by factors such as gender, family background, attitudes, previous academic background, location as well as the type of the course they enrolled. ("Tracer Study on Aimst University," 2012)

The Internat Thesaurus 2005 defines a tracer study as an impact assessment tool where the "impact on target groups is traced back to specific elements of a project or programme so that effective and ineffective project components may be identified." In educational research, the tracer study is sometimes referred to as a graduate or alumni survey since its target group is former students (Millington, 2003). Schomburg (2003, p.36) notes that graduate surveys are popular for "analysis of the relationship between higher education and work." They provide quantitative-structural data on employment and career, the character of work and related competencies, and information on the professional orientation and experiences of their graduates.

Curriculum evaluation is essential to any program to ensure that its content remains relevant, of high quality and is in tune with the demand of the job market. One of the ways institutions does this is through tracer studies (Peng and Zhang, 1997) (as cited by Tobergte and Curtis 2013). The University graduate tracer study provides the desirable information as to the graduates' career after graduation and as to what is happening to them when they join the world of work. It is equally important to find out how effective and adequate were the trainings provided by this institution in the enhancement of their skills and competencies and the development of their work-related values. This tracer study is also a way which can provide valuable information for evaluating the usefulness and relevance of these skills, competencies, and work-related values to their present jobs.

\subsection{Theoretical Support}

The study was supported by the neoclassical of Keynesian theory which was propounded by John Maynard Keynes. The neoclassical theory explains unemployment as a temporary problem and as a result of inflation. Accordingly, it views that reduction of inflation would stabilize the economy, which in turn would lead to economic growth and thus reduction in unemployment. Ergo, this approach considered as the tackling of inflation through direct state intervention more important than reduction of unemployment, which would somehow happen automatically. In addition, this theory applies to its analysis of the labor market the principle of supply and demand and treats unemployment as a disequilibrium phenomenon that comes out from the persistence and continuity of wages at a higher level than that which clears the labor market. Some of the reasons why labor market cannot adjust to full are the minimum wage legislation, union bargaining, and efficiency wages among others (where higher wages produce better workers from the employment pool) (Verona, 2013).

Another theory where this study was anchored was the Human Capital Theory of Weber (2002). This theory recognizes the positive relationship between investments in the development of human beings and economic growth. The idea of investment in skills, competencies and work-related values is paramount. Weber (2002) contends that there is a strong empirical evidence of the inverse relationship between unemployment and educational level which means that the rise in educational level will likely decrease unemployment rates. In addition, he also averred that the education is a key factor to the incidence and duration of unemployment because labour markets are not perfectly flexible. This, therefore, may result in a reduced demand for unskilled labour and thus unemployment. A need for human investment in higher education is therefore necessary for the advancement of the labour market. The human capital theory views skills as commodities and operates around the notion that an individual will choose to invest in his/her own education on the basis that such an investment will result in enhanced marketable skills (Tobergte \& Curtis, 2013).

Lastly, another theoretical support for this study was the Labor Market Theory by (Lindley, 1996) In this theory, he explains that some educational and training measures aim to make the labour market work better by presenting better information about courses, qualifications and people's achievements. This is through rationalising the available information and simplifying it for understand ability and clarity among the different actors in the system. Hence measures have to be taken to raise the quality and accessibility of information about an individual's performance and transitional activity in moving from school to work. However, students can make their own choices. Research in Britain suggests that young people are extremely resourceful, capable of adjustment to abrupt changes in status and manage to reconcile themselves to the reality of the labour market.

\subsection{Statement of Research Focus}

This research project determined the factors associated with the job placement of the graduates of Bachelor of Arts in English Language (ABEL) and Bachelor of Science in Mathematics (BSM) of the College of Arts and Sciences (CAS) of Central Bicol State University of Agriculture (CBSUA) Calabanga Campus from 2011-2015. Specifically, this study were guided by the following objectives:

1.3 Create personal and home profile of the respondents in terms of: age, sex, civil status, college, course, year graduated, parental education, and, parental occupation;

1.4 Find out the job placement profile of the respondents in terms of: Job after graduation; Present employment; Employment Status; Nature of Employment; Reasons if unemployed; factors 
facilitating acquisition of first job and Means of Getting a job;

1.5 Determine useful and relevant competencies/skills and work-related values developed by CBSUACalabanga considered by the respondents in meeting the demands of their present work;

1.6 Determine how effective and adequate were the trainings on competencies/skills and work-related values provided by the University that contributed in meeting the demands of their present work.

\subsection{Significance of the Study}

This tracer study was deemed beneficial and valuable to the following sectors and group of persons:

Commission on Higher Education (CHEd). The findings of this study can aid the curricular committee of Higher Education Institutions (HEIs) in the review and revision of the programs to be offered and served to the students which are matched and best fitted to the demands in the job market.

School Administrators. The result of this investigation may provide significant inputs and guidance to school administrators in enhancing the employability of their graduates and improving the program of studies through research-based recommendations. Findings of this study could serve as the benchmark for curriculum reviews and revisions for the internationalization and academization of graduates to be attuned with the movements and drifts in the global arena.

Faculty. This can serve as a jumpstart to the faculty in the planning and designing of their syllabi to consider the integration of an all-inclusive learning experiences and career services.

Students. This will serve as their basis in cultivating their skills and advancing their knowledge so they can take active part in the global competition and attain a full, decent and productive employment after graduation.

Future Researchers. The findings of this investigation can provide future researchers reference a point in improving the current programs and designing new programs that are addressing real training needs to produce highly competent and productive professionals.

\subsection{Scope and Delimitation}

This tracer study focused on investigating the graduates' personal and home characteristics, job placement profile, the skills/competencies and work-related values they acquired that are useful and relevant to enhancing their employability, and the trainings provided by the university that enhanced these skills/competencies and work-related values to help them meet the demands of their present work. This covered only the two programs of the College of Arts and Sciences at Central Bicol State University of Agriculture (CBSUA) which were the Bachelor of Arts in English Language (ABEL) and Bachelor of Science in Mathematics (BSM). The survey extended only to those who enrolled and finished their courses from School Year 2011 to 2015. The study was delimited solely to the students of the College of Arts and Sciences of CBSUA-Calabanga Campus and thus eliminated those from other campuses and those taking other courses.

\section{Materials and Methods}

\subsection{Research Design}

The research project employed the survey research method to tack the graduates' employment profile and the link between their schooling and employment. The method was also used to appraise the effectiveness, relevance, and adequacy of the curriculum in meeting the demands of their present work.

\subsection{Locus of the Study}

The study was conducted in one of the campuses of Central Bicol State University of Agriculture (CBSUA) in Bicol, the Calabanga campus. CBSUA has four campuses: the Calabanga, Sipocot, Pasacao, and Pili (main campus). The Calabanga Campus which is the locale of the study has three colleges, i.e., College of Education, College of Industrial Technology, and College of Arts \& Sciences. Specifically, the survey was conducted among the graduates of two programs of the College of Arts and Sciences.

\subsection{Population and Sampling}

The study initially targeted to obtain the entire population of both ABEL and BSM graduates within the covered period, however, it ended up generating only a sample of 188 for the 2 programs with a total of 123 ABEL and 65 BSM which is $96.85 \%$ of the ABEL graduates and $91.55 \%$ of the BSM graduates. This, however, falls within the expected response rate of 30 to 60 percentage recommended by (Schomburg, 2003) on the conduct of graduate tracer studies.

\subsection{Data Collection Techniques}

The study utilized a researcher-made questionnaire crafted through item pooling from the CHEd, PNU, and Lyceum of the Philippines tracer study questionnaires which was slightly modified for the purpose of this study. Names, addresses, and contact numbers of the graduates were obtained from the placement and alumni office for 
facility of trailing. The researcher administered some of the questionnaires using electronic mail or e-mail or face book messages to the graduate-messages for most of the graduate respondents use computers in their offices or companies. Thus, it is easier to communicate with them and solicit their participation in the study. The researcher also asked for the help and assistance of friends, relatives and currently enrolled students from the time of data gathering for the personal delivery of the questionnaire to the identified respondents.

The questionnaire is divided into three sections: Section 1 is on personal and home profile which includes age, sex, civil status, the college where they belong, course taken, the year graduated, parental education and parental occupation. Section 2 is on Job Placement Profile which consists of details about the graduates' job after graduation, present employment, status and nature of employment, reasons for employment if employed, factors facilitating acquisition of first job, and means of getting a job if employed. Section 3 on effectiveness, relevance, and adequacy of the curriculum in meeting the demands of their work.

\subsection{Data Analysis}

Data analysis in this study primarily employed descriptive statistics such as frequency and percentage as well as weighted mean and ranking. Interpretations of means were based on a 4-point Likert scale, where 4 means very much, 3 means, much, 2, a little, and 1 not at all.

\subsection{Validity and Reliability}

To define the content validity of the questionnaires, the researcher consulted the experts in instrument development in the university consisting of the research director and the advisor professors. Their suggestions and recommendations were noted and integrated in the final form. The questionnaire was also pretested with sampled population or graduates of other course in the University who were not the actual respondents of the study. Thereafter, the results were subjected to reliability testing. Hence, the researcher performed the Chronbach's alpha coefficient which resulted to a value of .956.

\section{Results and Discussion}

\subsection{Demographic Information}

The home and personal characteristics were examined along the following: age, sex, civil status, parental education and occupation. It indicated that participants in the study were mostly aging between 22 and 29 (61.8\% for ABEL and $66.2 \%$ for BSM). Over half were female and still single. Of the total 139 female from both courses, 94 (or 76.4\%) of which were from ABEL, while, 45 (or 69.2\%) were from BSM. The largest percentages in terms of parental education of their mothers $(33.5 \%)$ and fathers $(39.4 \%)$ had only completed high school. About $60 \%$ of their mothers were unemployed with some who only owns a small business $(13 \%)$, engaged in farming and fishing $(5 \%)$, and teaching $(4 \%)$. Their fathers were engaged into occupation as driving $(21 \%)$, farming and fishing (19\%) and carpentry and labor $(13 \%)$.

\subsection{Job Placement Profile}

The Job placement profile of the ABEL and BSM graduates were examined in this study along several aspects including the status of their job after graduation, present employment, type of employment, nature of employment, reasons for unemployment, factors facilitating acquisition of their first job and the means of getting their job. Data are shown in Tables 1-4.

\subsubsection{Job After Graduation}

The status graduates' job after graduation, (Table 1) revealed a large percentage of respondents who landed on the job related to the course they have completed (126 or $67.0 \%)$ than those non-related $(62$ or $33.0 \%)$. Percentage-wise, there were more from ABEL (70.7\%) compared to BSM (60.0\%) whose type of jobs were related to the course completed. Among the 123 ABEL students, $72 \%$ of them only searched their job in less than a month, the other $23.6 \%$ were employed within the period of 1-6 months. This was almost the case with the BSM graduates, there were $47.7 \%$ who were employed in less than a month and $46.2 \%$ within $1-6$ months. Thus, on the average, most $(63.8 \%)$ of their employment were acquired only within a short period of time, i.e., less than a month. As to their stay in first job, the great majority of the ABEL (78 or 63.4\%) and BSM (49 or $75.4 \%$ ) graduates stayed only for 1-6 months in the company/institution they served with. In total, about $68 \%$ had this length of stay, while, only 2 or $1.1 \%$ continued up to 3 years to less than 4 years. 
Table 1. Job Placement Profile along Job after Graduation

\begin{tabular}{lccc}
\multicolumn{1}{c}{ VARIABLES } & $\begin{array}{c}\text { ABEL } \\
(\mathrm{n}=123)\end{array}$ & $\begin{array}{c}\text { BSM } \\
(\mathrm{n}=65)\end{array}$ & $(\mathrm{N}=188)$ \\
\hline $\begin{array}{l}\text { Types of Job } \\
\text { Related to the course completed }\end{array}$ & $87(70.7 \%)$ & $39(60.0 \%)$ & $126(67.0 \%)$ \\
$\quad$ Not related to the course completed & $36(29.3 \%)$ & $26(40.0 \%$ & $62(33.0 \%)$ \\
Length of Job Search & & & \\
$\quad$ Less than a month & $89(72.0 \%)$ & $31(47.7 \%)$ & $120(63.8 \%)$ \\
1-6 months & $28(23.0 \%)$ & $30(46.2 \%)$ & $58(30.9 \%)$ \\
7-11 months & $0(0.0 \%)$ & $2(3.1 \%)$ & $2(1.1 \%)$ \\
1 year to less than 2 years & $6(5.0 \%)$ & $2(3.1 \%)$ & $8(4.3 \%)$ \\
Stay in First job & & & \\
$\quad$ Less than a month & $19(15.4 \%)$ & $5(7.7 \%)$ & $24(12.8 \%)$ \\
1-6 months & $78(63.4 \%)$ & $49(75.4 \%)$ & $127(67.6 \%)$ \\
7-11 months & $5(4.1 \%)$ & $6(9,2 \%)$ & $11(5.9 \%)$ \\
1 year to less than 2 years & $17(13.8 \%)$ & $3(4.6 \%)$ & $20(10.6 \%)$ \\
2 year to less than 3 years & $2(1.6 \%)$ & $2(3.1 \%)$ & $4(2.1 \%)$ \\
3 year to less than 4 years & $2(1.6 \%)$ & $0(0.0)$ & $2 \%(1.1 \%)$ \\
\hline
\end{tabular}

3.3.2. Present Employment

The data (Table 3) on the respondents' present employment revealed that the plurality (39.8\%) of ABEL respondents are now working as office employees. Some are clerks/cashiers $(25.2 \%)$, others are teachers $(12.2 \%)$ and government employees (4.1\%). Employment for BSM, on the other hand, were concentrated along such occupations as accountants/account officers (26.2\%), clerks/cashiers (12.3\%), and teachers (10.8\%) and administrative/office assistants (10.8\%). The differential in unemployment, however, revealed a much higher percentage of 30.7 among BSM graduates and $11.4 \%$ for the ABEL. On the whole, highest percentage of employment were from those working as office employees $(26.6 \%)$, followed closely by those working as clerks/cashiers (20.7\%), and those engage in teaching (11.7\%). The average employment rate was $18.1 \%$.

\begin{tabular}{lccc}
\hline \multicolumn{3}{c}{ Table 2. Job Placement Profile as to Present Employment } \\
\multicolumn{1}{c}{ VARIABLES } & $\begin{array}{c}\text { ABEL } \\
(\mathrm{n}=123)\end{array}$ & $\begin{array}{c}\text { BSM } \\
(\mathrm{n}=65)\end{array}$ & $(\mathrm{N}=188)$ \\
\hline Office Employee & $49(39.8 \%)$ & $1(1.5 \%)$ & $50(26.6 \%)$ \\
Clerk/Cashier & $31(25.2 \%)$ & $8(12.3 \%)$ & $39(20.7 \%)$ \\
Teacher & $15(12.2 \%)$ & $7(10.8 \%)$ & $22(11.7 \%)$ \\
Accountant/Account Officer & $0(0.0 \%)$ & $17(26.2 \%)$ & $17(9.0 \%)$ \\
Administrative/Office Assistant & $0(0.0 \%)$ & $7(10.8 \%)$ & $7(3.7 \%)$ \\
Gov't Employee & $5(4.1 \%)$ & $0(0.0 \%)$ & $5(2.7 \%)$ \\
Sales Agent/Insurance Agent & $0(0.00)$ & $4(6.2 \%)$ & $4(2.1 \%)$ \\
Area/Branch Manager/Team Leader & $3(2.4 \%)$ & $0(0.0 \%)$ & $3(1.6 \%)$ \\
Networking & $2(1.6 \%)$ & $0(0.0 \%)$ & $2(1.1 \%)$ \\
Lending Company T.O. & $2(1.6 \%)$ & $0(0.0 \%)$ & $2(1.1 \%)$ \\
OFW & $1(0.8 \%)$ & $1(1.5 \%)$ & $2(1.1 \%)$ \\
Quality Control (pure foods) & $1(0.8 \%)$ & $0(0.0 \%)$ & $1(0.5 \%)$ \\
Unemployed & $14(11.4 \%)$ & $20(30.7 \%)$ & 34 \\
\hline
\end{tabular}

3.3.3. Status and Nature of Employment and Reasons for Unemployment

The frequency distribution of respondents according to their employment status and nature of employment is shown in Table 3. As to the type of employment, contractual employment had the largest proportion that went up to $31.5 \%$. Those on permanent status were relatively lower at $29.8 \%$ and casual at $18.6 \%$. Data by course showed that the number of regular/permanent employees among ABEL (35.0\%) was higher than BSM (20.0\%).

The predominance in number of graduates with contractual status was quite evident with BSM respondents (47.7\%) compared to ABEL (26.0\%). In terms of the nature of employment, the greater proportion were gainfully employed (81.9\%), 66.9 percent of which were from ABEL and 69.2\% were from BSM. The reasons for for some in not finding employment and for experiencing a long waiting period were just one and the same for both courses, i.e., that they did not actively look for it (47.1\%). This was the number 1 problem by half and almost half of the ABEL (50.0\%) and BSM (45.0\%) graduates respectively. Followed by some health related reasons $(20.6 \%)$ and the lack of advance and further study $(14.7 \%)$. 


\begin{tabular}{|c|c|c|c|}
\hline VARIABLES & $\begin{array}{l}\text { ABEL } \\
(n=123\end{array}$ & $\begin{array}{c}\text { BSM } \\
(n=65)\end{array}$ & $(\mathrm{N}=188)$ \\
\hline \multicolumn{4}{|l|}{ Type of Employment } \\
\hline Regular/Permanent & $43(35.0 \%)$ & $13(20.0 \%)$ & $56(29.8 \%)$ \\
\hline Casual & $34(28.0 \%)$ & $1(1.5 \%)$ & $35(18.6 \%)$ \\
\hline Contractual & $32(26.0 \%)$ & $31(47.7 \%)$ & $63(31.5 \%)$ \\
\hline \multicolumn{4}{|l|}{ Nature of Employment } \\
\hline Gainfully Employed & $109(66.9 \%)$ & $45(69.2 \%)$ & $154(81.9 \%)$ \\
\hline Unemployed & $14(8.6 \%)$ & $20(30.8 \%)$ & $34(18.1 \%)$ \\
\hline \multicolumn{4}{|l|}{ Reasons if Unemployed } \\
\hline Lack of advance or further study & $1(7.1 \%)$ & $4(20.2 \%)$ & $5(14.7 \%)$ \\
\hline Health related reason & $3(21.4 \%)$ & $4(20.0 \%)$ & $7(20.6 \%)$ \\
\hline Did not actively look for a job & $7(50.0 \%)$ & $9(45.0 \%)$ & $16(47.1 \%)$ \\
\hline $\begin{array}{l}\text { Family concern/ situation prevents me from } \\
\text { working }\end{array}$ & $1(7.1 \%)$ & $2(10.0 \%)$ & $3(8.8 \%)$ \\
\hline No job opportunity & $2(14.3 \%)$ & $1(5.0 \%)$ & $3(8.8 \%)$ \\
\hline
\end{tabular}

\subsubsection{Factors facilitating acquisition of first job}

Their reasons for acquiring their job and the means of getting it are reflected in Table 5. Results indicated that almost $83 \%$ acquired their job because of their area of specialization. The remainder had it because of the reputation of the school (11.7\%) and scholastic standing (5.9\%). In the survey of 188 graduates, 109 (or $88.9 \%$ ) of ABEL and 46 (or 70.8\%) of the BSM acquired their first job because their area of specialization. Only, 7 (or $5.7 \%$ ) and 15 (or 32.1\%) respectively for ABEL and BSM had their employment because of the reputation of the school.

\begin{tabular}{|c|c|c|c|}
\hline VARIABLES & $\begin{array}{c}\text { ABEL } \\
(\mathrm{n}=123)\end{array}$ & $\begin{array}{c}\text { BSM } \\
(\mathrm{n}=65)\end{array}$ & $(\mathrm{N}=188)$ \\
\hline \multicolumn{4}{|l|}{ Acquisition of First Job } \\
\hline Area of Specification & $109(88.6 \%)$ & $46(70.8 \%)$ & $155(82.4 \%)$ \\
\hline Scholastic Standing & $7(5.7 \%)$ & $4(6.2 \%)$ & $11(5.9 \%)$ \\
\hline Reputation of the School & $7(5.7 \%)$ & $15(32.1 \%)$ & $22(11.7 \%)$ \\
\hline \multicolumn{4}{|l|}{ Means of Getting a Job } \\
\hline Personnel office of hiring companies & $87(70.7 \%)$ & $35(53.8 \%)$ & $122(64.9 \%)$ \\
\hline Recommendation from friends and relatives & $8(6.5 \%)$ & $6(9.2 \%)$ & $14(7.4 \%)$ \\
\hline Media advertising & $3(2.4 \%)$ & $2(3.1 \%)$ & $5(2.7 \%)$ \\
\hline School placement office & $3(2.4 \%)$ & $2(3.1 \%)$ & $5(2.7 \%)$ \\
\hline Government placement office & $5(4.1)$ & $0(0.00)$ & $5(2.7 \%)$ \\
\hline Former Teacher recommendation & $3(2.4 \%)$ & $0(0.00)$ & $3(1.6 \%)$ \\
\hline
\end{tabular}

As to the means of getting a job, more than $60 \%$ of them got their job through the personnel of hiring companies. There were 70.7\% from ABEl and 53.8\% from BSM who corroborated this information. Only 14 were hired because of the recommendation from their friends and relatives. Some though government placement office (5), others through media advertising (5), school placement office (5) and recommendation from a former teacher (3).

\subsection{Competencies/Skills and Work-Related Factors}

The usefulness and relevance of the competencies/skills and work-related factors developed as well as the effectiveness and adequacy of the trainings provided by the University to meet the demands of their present work were likewise taken into account. Results of the survey are presented in Tables 5-9.

4.4.1. Usefulness and Relevance of Skills and Competencies to Job Placement

What has become the most useful (3.37) and relevant (3.36) skills for the graduates was communication skills. Followed by human relation skills with 3.34 and 3.31 mean scores respectively for usefulness and relevance. On the other hand, entrepreneurial skills as well as information technology skills were among the least useful with only 3.23 mean ratings obtained from the graduates. Critical thinking skills (3.18) and research skills (3.19) were reported to be the least relevant compared to other skills. Overall, the competencies and skills developed in the university were very much useful (3.29) and much relevant (3.24) as declared by the graduates. 
Table 5. Usefulness and Relevance of the following competencies and skills to graduates' present job

\begin{tabular}{|c|c|c|c|c|c|c|}
\hline \multicolumn{3}{|c|}{ USEFULNESS } & \multirow{2}{*}{ SKILLS/COMPETENCIES } & \multicolumn{3}{|c|}{ RELEVANCE } \\
\hline Rank & Mean & VI & & Mean & VI & Rank \\
\hline 1 & VM & 3.37 & Communication & 3.36 & VM & 1 \\
\hline 2 & VM & 3.34 & Human relation & 3.31 & VM & 2 \\
\hline 3 & VM & 3.31 & Research & 3.19 & M & 6 \\
\hline 6.5 & $\mathrm{M}$ & 3.23 & Entrepreneurial & 3.24 & M & 3 \\
\hline 6.5 & $\mathrm{M}$ & 3.23 & Information technology & 3.22 & $\mathrm{M}$ & 4 \\
\hline 4 & VM & 3.29 & Problem Solving & 3.20 & M & 5 \\
\hline \multirow[t]{2}{*}{5} & VM & 3.28 & Critical Thinking & 3.18 & M & 7 \\
\hline & VM & 3.29 & Composite Mean & 3.24 & M & \\
\hline
\end{tabular}

Legend:

$\begin{array}{cc}\text { Value Scale } & \text { Mean Range } \\ 4 & 3.26-4: 00 \\ 3 & 2.51-3.25 \\ 2 & 1.76-2.50 \\ 1 & 1: 00-1.75\end{array}$

\author{
Verbal Interpretation (VI) \\ Very Much (VM) \\ Much (M) \\ A Little (AL) \\ Not at All (NAA)
}

4.4.2. Usefulness and Relevance of Work Related Values to Job Placement

Among the list of work related values developed and impressed upon the students by the University (Table 6), love of God has been unanimously agreed by the graduates as the most useful and relevant. The second most useful was honesty and love for truth (3.39) and third was courage (3.36). As to relevance, courage (3.44) was the second and perseverance and hard work (3.42), third. On the contrary, creativity and innovativeness (3.17), fairness and justice (3.19) and supportiveness (3.19) were expressed by the respondents as not so useful compared to the other work related values. In addition nationalism (3.33), fairness and justice (3.34) and tolerance (3.35) were the least relevant skills in job placement. Overall, the respondents conveyed that these values experienced by them are both very much useful (3.38) and relevant (3.39) in finding their job.

Table 6. Usefulness/relevance of the following work related values to your present job

\begin{tabular}{|c|c|c|c|c|c|c|}
\hline \multicolumn{3}{|c|}{ Usefulness } & \multirow{2}{*}{ Particulars } & \multicolumn{3}{|c|}{ Relevance } \\
\hline $\mathrm{R}$ & $\mathrm{I}$ & WM & & WM & $\mathrm{I}$ & $\mathrm{R}$ \\
\hline 1 & VM & 3.42 & Love of God & 3.50 & VM & 1 \\
\hline 7.5 & VM & 3.31 & Self-reliant & 3.41 & VM & 4.5 \\
\hline 2 & VM & 3.39 & Honesty and love for truth & 3.41 & VM & 4.5 \\
\hline 12.5 & M & 3.25 & Punctuality & 3.39 & VM & 8 \\
\hline 7.5 & VM & 3.31 & Obedience to Superior & 3.37 & VM & 13.5 \\
\hline 4.5 & VM & 3.33 & Perseverance and hard work & 3.42 & VM & 3 \\
\hline 20 & M & 3.17 & Creativity and innovativeness & 3.38 & VM & 10 \\
\hline 3 & VM & 3.36 & Courage & 3.44 & VM & 2 \\
\hline 10.5 & VM & 3.28 & Professional Integrity & 3.38 & VM & 10 \\
\hline 10.5 & VM & 3.28 & Love for co-workers and others & 3.40 & VM & 6.5 \\
\hline 15.5 & $\mathrm{M}$ & 3.22 & Unity & 3.36 & VM & 16.5 \\
\hline 18.5 & M & 3.19 & Fairness and justice & 3.34 & VM & 19 \\
\hline 15.5 & M & 3.22 & Leadership & 3.37 & VM & 13.5 \\
\hline 12.5 & M & 3.25 & Tolerance & 3.35 & VM & 18 \\
\hline 15.5 & M & 3.22 & Efficiency & 3.37 & VM & 13.5 \\
\hline 18.5 & M & 3.19 & Supportiveness & 3.37 & VM & 13.5 \\
\hline 15.5 & $\mathrm{M}$ & 3.22 & Perseverance & 3.40 & VM & 6.5 \\
\hline 4.5 & VM & 3.33 & Self-discipline & 3.36 & VM & 16.5 \\
\hline 7.5 & VM & 3.31 & Nationalism & 3.33 & VM & 20 \\
\hline \multirow[t]{2}{*}{7.5} & VM & 3.31 & Open-mindedness & 3.38 & VM & 10 \\
\hline & VM & 3.28 & Total & 3.39 & VM & \\
\hline
\end{tabular}

Legend:

$\begin{array}{cc}\text { Value Scale } & \text { Mean Range } \\ 4 & 3.26-4: 00 \\ 3 & 2.51-3.25 \\ 2 & 1.76-2.50 \\ 1 & 1: 00-1.75\end{array}$

\author{
Verbal Interpretation (VI) \\ Very Much (VM) \\ Much (M) \\ A Little $(A L)$ \\ Not at All (NAA)
}


4.4.3. Effectiveness and Adequacy of Trainings for Skill and Competency Development

The perceptions of the respondents as to how effective and adequate were the trainings they received from the University is disclosed in Table 7. Figures suggest that critical thinking skills (3.40) topped the rank along the level of effectiveness, then followed by communication (3.38) human relation (3.38), information technology (3.38) skills. Consistently, these competencies, human relation (3.56) skills and communication skills (3.54) were the two highest rated items as to adequacy. Research skills (3.25) and problem solving (3.30), in contrast, received the lowest ratings along effectiveness, whereas, entrepreneurial and information technology skills (3.39) and problem solving (3.38) skills were for adequacy. All in all, the ratings revealed that those set of skills which were enhanced through trainings in the university were much effective (3.34) in helping them find a job and they were very much provided (3.44) by the University.

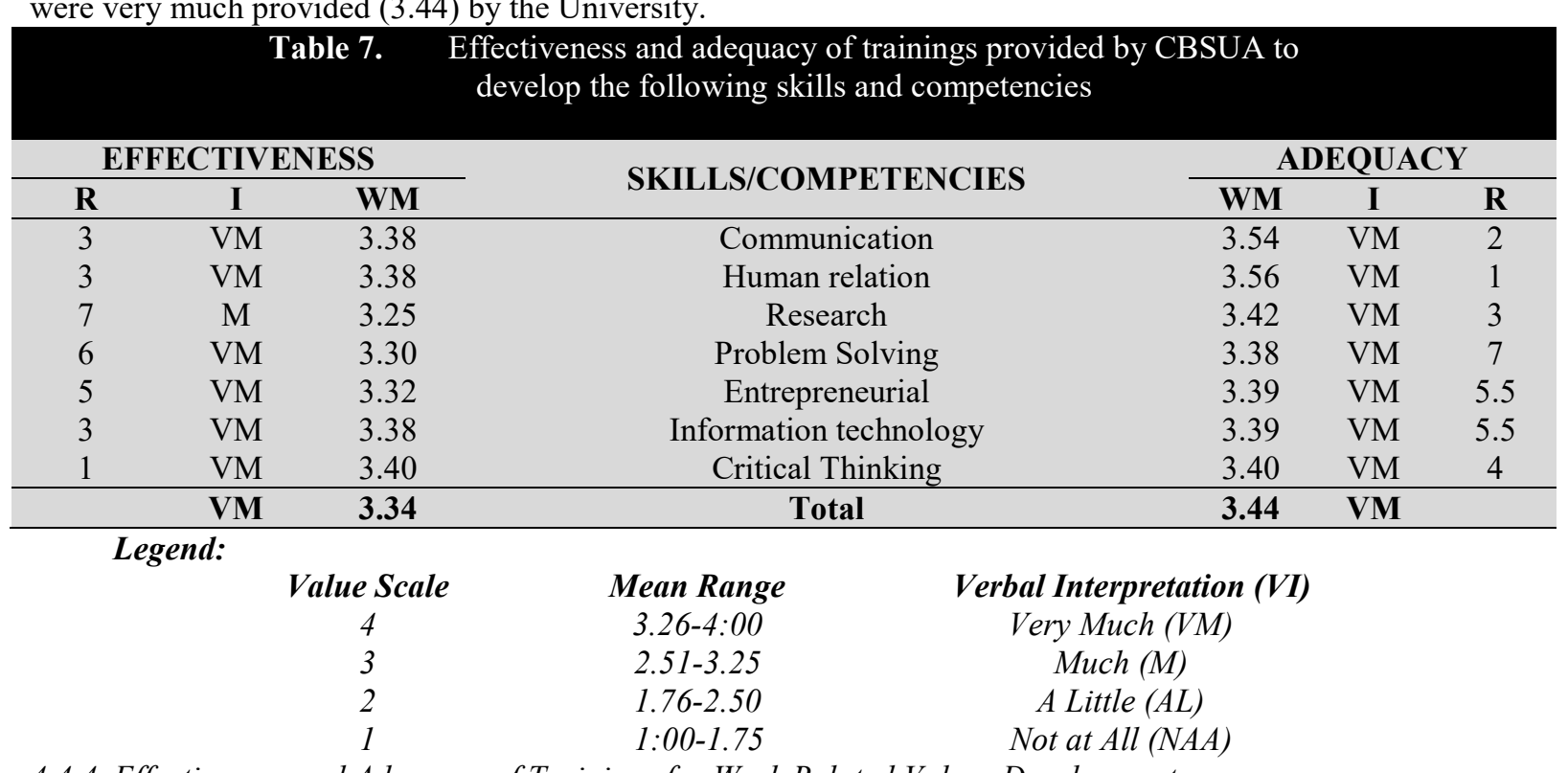

4.4.4. Effectiveness and Adequacy of Trainings for Work Related Values Development

Of the work related values acquired and experienced by the respondents in the University (Table 8), honesty and love for truth (3.60), love of God (3.54), obedience to superior (3.53) and self-discipline (3.53) emerged as the most effective in the actual job placement. Efficiency (3.38), tolerance (3.41) and leadership (3.43), in constrast, were the least effective. In terms of adequacy, however, they declared that the provision of trainings on selfdiscipline (3.64), self-reliance (3.63), perseverance and hard work (3.62) by the University were sufficient and enough. This runs contrary to their trainings on leadership (3.51), tolerance (3.52), and efficiency (3.52), which had as well been rated least adequate by the respondents. In general, all of the given work related values are effective (3.49) to job placement of the respondents and trainings provided in the University are adequate (3.57). 


\begin{tabular}{|c|c|c|c|c|c|c|}
\hline \multicolumn{3}{|c|}{ Table 9.} & \multicolumn{4}{|c|}{$\begin{array}{l}\text { Effectiveness and adequacy of trainings provided by CBSUA } \\
\text { to develop the following work-related values }\end{array}$} \\
\hline \multicolumn{3}{|c|}{ Effectiveness } & \multirow{2}{*}{ Particulars } & \multicolumn{3}{|c|}{ Adequacy } \\
\hline $\mathbf{R}$ & I & WM & & WM & I & $\mathbf{R}$ \\
\hline 2 & VM & 3.54 & Love of God & 3.59 & VM & 7.5 \\
\hline 6 & VM & 3.52 & Self-reliant & 3.63 & VM & 2 \\
\hline 1 & VM & 3.60 & Honesty and love for truth & 3.58 & VM & 9 \\
\hline 14.5 & VM & 3.46 & Punctuality & 3.55 & VM & 11 \\
\hline 3.5 & VM & 3.53 & Obedience to Superior & 3.53 & VM & 17 \\
\hline 8 & VM & 3.50 & Perseverance and hard work & 3.62 & VM & 3 \\
\hline 6 & VM & 3.52 & Creativity and innovativeness & 3.54 & VM & 14.5 \\
\hline 8 & VM & 3.50 & Courage & 3.61 & VM & 4 \\
\hline 6 & VM & 3.52 & Professional Integrity & 3.54 & VM & 14.5 \\
\hline 12 & VM & 3.48 & Love for co-workers and others & 3.59 & VM & 7.5 \\
\hline 8 & VM & 3.50 & Unity & 3.54 & VM & 14.5 \\
\hline 11.5 & VM & 3.49 & Fairness and justice & 3.60 & VM & 5.5 \\
\hline 18 & VM & 3.43 & Leadership & 3.51 & VM & 20 \\
\hline 19 & VM & 3.41 & Tolerance & 3.52 & VM & 18.5 \\
\hline 20 & VM & 3.38 & Efficiency & 3.52 & VM & 18.5 \\
\hline 16.5 & VM & 3.44 & Supportiveness & 3.57 & VM & 10 \\
\hline 14.5 & VM & 3.46 & Perseverance & 3.54 & VM & 14.5 \\
\hline 3.5 & VM & 3.53 & Self-discipline & 3.64 & VM & 1 \\
\hline 16.5 & VM & 3.44 & Nationalism & 3.56 & VM & 11 \\
\hline \multirow[t]{2}{*}{11.5} & VM & 3.49 & Open-mindedness & 3.60 & VM & 5.5 \\
\hline & VM & 3.49 & Total & 3.57 & VM & \\
\hline
\end{tabular}

Legend:

Value Scale
4
3
2
1

Mean Range
$3.26-4: 00$
$2.51-3.25$
$1.76-2.50$
$1: 00-1.75$

\author{
Verbal Interpretation (VI) \\ Very Much (VM) \\ $\operatorname{Much}(M)$ \\ A Little $(A L)$ \\ Not at All (NAA)
}

\subsection{Discussions}

Data on the home and personal profile of the respondents indicate the predominance of female over male respondents, while, both the ABEL and BSM graduates were generally young and single at the time of the respective surveys. Most of them belong to economically-challenged family with parents who only generally received secondary education. The huge number of non-working parents of these graduates may imply a worsening economy of the country or the mounting illiteracy rate owing to the lack of value paid for education.

As to the job placement profile, majority of the graduates somehow enjoy productive employment though many of them are contractual which is expected, of course, among beginners. It is worthy to note that it did not take them so long to search for a job. However, it can then be deduced from the findings that the main reason for unemployment of some of the graduates is still within their control and can just be solved by due diligence. It could be harder, of course, if it is due to unavailability of job opportunity or because of some health related reasons, while not actively looking for it or a family concern or situation could just be solved by persistence and determination. This is in line with De Guzman (as cited by Buama, 2018) states that, in the workplace, professionalism is expected. The problem is that even after college, the person is still not prepared to work. Many employees are too immature, they cannot even pass interviews. So it ended up with countless numbers of jobless all waiting in vain for that little luck in looking for a job. On the other hand, older people experience most age discrimination. However, it also takes place against young people. It is now unlawful for an employer to impose a lower age limit when recruiting, unless this age restriction can be objectively justified or is imposed by law.

Among the skills and competencies found very much relevant/useful to their job placement were communication skills and human relation skills. Graduates received the most adequate trainings on human relation, however, they viewed critical thinking skills as the most effective contributory factor in facilitating employment. These results explain the significance of employability skills specifically, communication, human relation, and critical thinking. There were wealth of literatures which point to these skills and competencies as requisites to almost all aspects of work including but not limited to, establishing interpersonal relationship, 
customer relation, in sales talks among others, and over and above, employers have preference over applicants with impressive speaking ability than those with poor ones. This was corroborated by Archer and Davidon (2008) who expressed that regardless of the size of the company, 'soft skills' (e.g. communication skills and teamworking) were perceived to have more weight than technical or 'hard skills' (e.g. a good degree qualification, IT skills). In addition, the Caribbean Basin Initiative (CBI, 2009) contributed to the discussion on employability in their report, 'Time well spent: Embedding employability in work experience'. They enumerated 8 indispensable skills in employment, namely: positive attitude, self-management, teamwork, business and customer awareness, problem solving, communication and literacy, application of numeracy, and, application of information technology. In the research report 'How much does higher education enhance the employability of graduates?' (Mason and Williams and Cranmer, 2006), the concept of employability centered on the development of communication, numeracy, information technology, and learning how to learn.

The work-related values that contributed the most to their employment and that had been developed in the university was the love of God. The work related values which were so effective to job placement were honesty and love for truth, love of God, obedience to superior and self-discipline. Trainings on self-discipline, selfreliance, as well as perseverance and hard were sufficient.

\subsection{Conclusions and Recommendations}

From the foregoing findings, the following were the inferences that: there is still a need to improve the employment rate particularly of the BSM graduates; students need relevant employment skills and work related values to enhance their employability; curricular reviews and revisions are necessary to match skills/competencies as well as work-related values developed in the university with the industry or job market requirement; the design of the courses do not emerge from a strong partnership with the employer organizations. It is therefore recommended that educational strategies, innovative leadership and institutional reforms that take into account the current trends in the global market should be the center of strategic planning and employability program integration; a students should be provided with an all-inclusive learning environment and career services (such as placements, internships and work-based learning opportunities) that can be enhanced and resourced to promote employability more effectively; partnerships between the University and employer organization need to be effective, sustained and equitable.

\section{References}

Archer, W. and Davidon, J. (2008). Graduate employability: What do employers think and want? London, the Council for Industry and Higher Education (CIHE).

Buama, C. A. C. (2018). Tracer and Employability Study: BS Tourism Graduates of Laguna State Polytechnic University Los Banos Campus. Retrieved from https://www.knepublishing.com/index.php/KneSocial/article/view/2383/5246\#

CBI, U. U. (2009). Future Fit -preparing graduates for the world of work. ISBN: 978-0-85201-698-5Yorke.

Development, I. T., Youth, N., The, S., Youth, N., \& Nysp, T. (2003). A TRACER STUDY OF GRADUATES, $1-44$.

Kevin Lowden, Stuart Hall, D. D. E. and J. L. (2011). Employers' Perception of the Employability Skills of New Graduates. Published by Edge Foundation.

Lindley, R. . (1996). The school-to-work transition in the United Kingdom. International Labour Review, 1(136), $159-181$.

Mason, G. and Williams, G. and Cranmer, S. (2006). Employability skills initiatives in higher education: what effects do they have on graduate labour outcomes? London: National Institute of Economic and Social Research. GLM293.

Tobergte, D. R., \& Curtis, S. (2013). No Title No Title. Journal of Chemical Information and Modeling, 53(9), 1689-1699. https://doi.org/10.1017/CBO9781107415324.004

Verona, L. (2013). A Tracer Study of the Employment Status of PUPQC AY 2004-2005. Retrieved July 30, 2018, from https://www.scribd.com/doc/50720521/A-Tracer-Study-of-the-Employment-Status-of-PUPQCAY-2004-2005

Weber, E. (2002). Shifting to the right: The evolution of equity in the South African Government's Developmental and Education Policies 1990 - 1999. Comparative Education Review, 46. 
DARIEL A. PALMIANO is a native of Pili, Camarines Sur. He was born in October 4, 1978. He earned his AB Philosophy, minor in Religious Education (Excellence in Philosophy) at the Holy Rosary Minor Seminary in Naga City. He obtained his MA in Public Administration (Academic Excellence) and $\mathrm{PhD}$ in Human Resource Management (Academic Excellence) at Naga College Foundation, where he currently teaches graduate classes. Aside from teaching, Dr. Palmiano has assumed various administrative posts at NCF: Campus Ministry Coordinator (2003-2005), Director of Student Affairs (2009-2011). At present, he is the Dean of the College of Arts and Science of Central Bicol State University of Agriculture-Calabanga Campus. 